\title{
PHARMACOLOGICAL ANALYSIS OF OBNOXIOUS WATER WEED: EICHHORNIA CRASSIPES (MART.) SOLMS
}

\author{
S. Khalid ${ }^{1,2 *}$, S. Shaheen ${ }^{1}$, K. Hussain ${ }^{3}$, M. N. Shahid ${ }^{4}$ and S. Sarwar ${ }^{1}$. \\ ${ }^{1}$ Lahore College for Women University, Jail Road, Lahore. Pakistan. \\ ${ }^{2}$ Institute of Agricultural Sciences, University of the Punjab, Lahore. Pakistan. \\ ${ }^{3}$ Department of Bioinformatics and Biotechnology, Government College University, Faisalabad, Pakistan. \\ ${ }^{4}$ Department of Botany, Division of Science and Technology, University of Education, Township, Lahore, Pakistan. \\ *Corresponding author's Email: sanakhalidpu@gmail.com
}

\begin{abstract}
Eichhornia crassipes (Mart.) Solms, commonly known as water hyacinth, an aquatic plant coined to diverse activities including its role as an obnoxious weed with tremendous economic and aesthetic implications. The aim of the current experiment was to explore antimicrobial, antioxidant and phytochemical properties of this weed while using different non-polar solvents viz., petroleum ether, chloroform and polar solvents i.e., methanol and aqueous (distilled water) solvent extracts of root, stem and leaf of $E$. crassipes. Disc diffusion method was employed to analyse the antifungal activity against two fungi (Penicillium italicum and Botrytis cinerea) and antibacterial activities against two bacteria viz. Xanthomonas axonopodis and Bordetella pertussis. The extracts of weed showed significant activity against these two fungi and two bacteria when compared to standard. Maximum antifungal and antibacterial potential was recorded in leaf chloroform extract against $B$. cinerea $(29 \mathrm{~mm})$ and in leaf methanol extract against $B$. pertussis $(17 \mathrm{~mm})$ respectively among other extracts. Moreover, antioxidant potential of weed also showed the presence of significant secondary metabolites. Phytochemical analysis indicate presence of alkaloids, coumarins, terpenoids, tannins and flavonoides and absence of saponins, anthrax-quinones, phlobatanins and cardiac glycosides by standard procedures. These results also depict the significance of the plant in pharmaceutical industry.
\end{abstract}

Key words: Eichhornia crassipes, antibacterial activity, antioxidant activity, phytochemical analysis.

\section{INTRODUCTION}

Water hyacinth (Eichhornia crassipes Mart. Solms) has been acknowledged as world's most pervasive, most productive, free floating and selfcompatible, allowing selfed seed to be produced in abundance in populations monomorphic for style morph (Center et al., 1999; Barrett, 2015). Numerous studies, however, has been carried out to explore its beneficial role in nature e.g. by evaluation of antimicrobial, antioxidant and phytochemical properties in a similar vein as in medicinal or aromatic plants to outweigh its negative role and reported that this weed has a myriad of metabolites. Classic work of Edwards et al. (1985) and recent reports claim use of this weed for feed formulations and extensive role in phyto remediation and in removing greenhouse gases (Agunbiade et al., 2009; Jafari, 2010; Li et al., 2015; Pandey, 2015; Attermeyer et al., 2016). Recently, it has been documented that aqueous extracts of leaves of $E$. crassipes has active constituents which significantly enhanced resistance against pathogen Lactococcus garvieae in prawn (Chang and Chen, 2016). Extracts of different parts of E. crassipes plant in different organic or inorganic solvents were tested on mice models which were reported to have antitumor, anti- ulcerogenic and anti-inflammatory effects (Sanitha, 2005; Ali et al., 2009). Besides, scientists have emphasized how little was known about the antioxidant activity of this weed and opined that evaluation of its antioxidant potential and radical scavenging activity is of current interest; subsequently, it can be used to retard the peroxidation of lipid, which ultimately deteriorate the food, decreases its nutritional value as well as functional properties, ultimately leads to the cancer and other chronic diseases by damaging the human tissues (Yagi, 1987; Yen and Chen, 1995; Surendraraj et al., 2013). Extensive use of synthetic antioxidants to control the peroxidation of lipid in foods, have increased the health risks due to toxicity (Linderschmidt et al., 1986; Sobedio et al., 1991; Olukemi et al., 2005). Consumers, however, over the time avoiding such foods subsumed with chemicals and stipulate the replacement of synthetic antioxidants with natural one. Therefore, exploitation of new sources of natural antioxidants with these dangerous preservative has attracted increasing attention and plants have always been recommended as best source because they produce antioxidants (nutrients in food) motivated by oxygen and sun light, and slow the oxidative damage to our body by controlling it. 
Arguably, oxidative damage induced by free radicals (singlet oxygen, superoxide anion radicals and hydroxyl radicals) has been reported to imbalance the prooxidants and antioxidants ultimately leading to the destruction or modification of macromolecules (DNA, proteins, lipids, carbohydrates etc.) in biological systems. Furthermore, secondary metabolites in plants (alkaloids, terpenoids and phenolics), also known as phytochemical (bioactive compounds) have different metabolic activities, which have been reported to have defence action against damage caused by free radicals by mitigating harmful effects of free radicals hence act as antioxidants. For example, various biochemical and antimicrobial activities, in plants, has been listed for flavonoids (group of polyphenolic substances) which exert antioxidant activity through radical scavenging, protects membranes and metal ion chelation (Kumar et al., 2013; Kumar and Pandey, 2013; Liu et al., 2010; Rajeshwari et al., 2014). Similarly, Kumar et al. (2014) also opined that leaf aqueous extracts of E. crassipes have potent antioxidant, antimicrobial, cytotoxic and hepatoprotective activity in vitro and in vivo. Phytochemicals though considered as large and diverse group of compounds of natural origin, yet they have been reported to have no role in nutrition beside work together with other fibre and active compounds of food to protect the body from diseases. Many research reports gathered for importance of medicinal plants are in confirmatory with this view that these plants lack nutrition (Pramila et al., 2014). Therefore, attempt was made for preliminary antimicrobial, antioxidant and phytochemical assessment of different parts of E. crassipes which may be used in drugs manufacturing and may prove beneficial for humanity by employing in drugs manufacturing.

\section{MATERIALS AND METHODS}

Sample collection and extraction: $E$. crassipes whole plant samples were collected from the pond of Jinnah Garden Lahore, Pakistan and different parts of plant were dried after thorough washing and saved in labelled amber colored bottles. The dried powdered plant material was extracted in different non-polar solvents viz., (i) petroleum ether, (ii) chloroform and polar solvents i.e., (iii) methanol (iv) distilled water extracts by following maceration method (Fig. 1).

Antimicrobial Activity: Above mentioned solvents were used for extraction of different parts of E. crassipes (root, stem and leaf) were also employed to explore their antimicrobial feature and different readings of inhibitory zones against two fungal pathogen and two-gram negative bacteria (Fig. 2). These observations were recorded and compared with reference to standard disc zones.
Antifungal and antibacterial activity: Antifungal and antibacterial activity of the free floating E. crassipes, in which all crude extracts were tested, was performed by adopting the methodology of Ferreria et al. (1996). Test microorganism employed in the study were two fungal pathogens viz., Penicillium italicum and Botrytis cinerea and two bacterial strains viz., Xanthomonas axonopodis and Bordetella pertussis. After preparation of slants for bacteria and fungus (Qadeer et al., 1990) their respective inoculums were prepared. Thereafter, the respective growth media petri-plates were prepared for the measurement of antimicrobial efficacy of extract of specified plant. The petri plate was divided into two sections. In each section the crude extract of different plant parts was poured with the help of sterilized dropper into their respective uniform hole of $0.5 \mathrm{~mm}$. Whereof, in the second and third series of experiments pure solvent and commercially available standard antibiotic disc was placed in the hole as follows (1) Ampicillin disc (10 $\mu \mathrm{g})$ against Xanthomonas axonopodis (2) Amikacin disc (30 $\mu \mathrm{g}$ ) against Bordetella pertussis (3) Fucanazole (23.75 $\mu \mathrm{g})$ against Penicillium italicum and (4) Kanamycin disc against Botrytis cinerea under aspect conditions respectively. The inhibited zone (measured with the aid of vernier calliper, $\mathrm{mm}$ in diameter) became prominent after the required incubation time of bacteria and fungi i.e., 24 and 48 hours respectively.

Antioxidant activity: The total antioxidant capacity was assayed for all the extracts by adopting the method devised by Prieto et al. (1999). The reaction mixture (100 $\mu 1$ of each solution $+1900 \mu$ l of reagent solution) was incubated at $95^{\circ} \mathrm{C}$ for $60 \mathrm{~min}$. Readings were recorded at $\mathrm{A}_{695} \mathrm{~nm}$, after cooling the samples at room temperature. The antioxidant activity of Beta hydroxyl toluene (BHT; $0.5 \mathrm{mg} \mathrm{mL}^{-1}$ ) was also assayed for comparison. The scavenging activity was calculated by the following formula:

$$
\text { Total antioxidant capacity }=1-\frac{\mathrm{A} 1}{\mathrm{~A} 0}
$$

Where A1 was the noted for absorbance of the sample in the presence of scavenger and A0 was recorded for the absorbance of control. The prepared extract of plant fractions in different solvent was used to evaluate the free radical scavenging activity that react with the stable radical DPPH (2,2-diphenyl-1-picrylhydrazyl radical) by following the method established by Erasto et al. (2004) at $\mathrm{A}_{517} \mathrm{~nm}$. Control devoid of plant extracts and contained only reagents.

DPPH radical scavenging activity (\%)

Where:

$$
=\frac{\text { A control }- \text { A extract }}{\text { A control }} \times 100
$$

- 'A control' was noted as absorbance of DPPH solution with no plant extract 
- 'A extract' was noted as absorbance of tested extract.

Readings were taken in triplicate.

Phytochemical tests: Furthermore, plant parts extracts were subjected to phytochemical analysis for the assessment of secondary metabolites viz., alkaloids, saponins, anthraquinones, coumarins, terpenoids, flavonoids, tannins, phlobatannins and cardiac glycosides for their presence or absence in the particular extract (Jamil et al., 2012). Data was collected in triplicate and results were noted down as an average of three replicates (Snedecor and Corchan, 1980).

\section{RESULTS AND DISCUSSION}

Antifungal Activity: Data presented in Table 1 depicted that antifungal activity against $P$. italicum and $B$. cinerea with various non-polar and polar solvents extracts of $E$. crassipes (Figs. 3\&4). For the $P$. italicum root extracts in petroleum ether $\left(24 \pm 1.00^{\text {a }} \mathrm{mm}\right)$, aqueous extracts of stem $\left(20.3 \pm 1.52^{\mathrm{a}} \mathrm{mm}\right)$ and chloroform extracts of leaf $\left(23 \pm 1.00^{\text {a }} \mathrm{mm}\right)$ showed maximum value for inhibitory zone. Whereof, chloroform extract of both root and leaf depicted minimum inhibitory zone i.e., $11 \pm 1.00^{\mathrm{d}} \mathrm{mm}$ and $11 \pm 1.00^{\mathrm{b}} \mathrm{mm}$ respectively. In contrast, chloroform extracts of leaf and stem showed maximum zone of inhibition $\left(29 \pm 1.00^{\mathrm{a}}\right)$ and $\left(15 \pm 1.00^{\mathrm{a}}\right)$ respectively, against the fungus $B$. cinerea. Furthermore, root aqueous extracts showed maximum zone of inhibition $(24 \pm 1.00$ $\mathrm{mm})$ closely followed by leaf extracts in distilled water $\left(24.3 \pm 1.52^{\mathrm{b}}\right)$ whilst, petroleum ether extracts of both leaf and stem showed similar and minimum inhibitory zone i.e., $6 \pm 1.00^{\mathrm{c}} \mathrm{mm}$. However, petroleum ether and chloroform extracts of root showed transitional values of zone of inhibition i.e., $10 \pm 1.00^{\mathrm{b}} \mathrm{mm}$ and $8 \pm 1.00^{\mathrm{c}} \mathrm{mm}$ respectively for $B$. cinerea.

Antibacterial Activity: In this study antibacterial activity against two gram negative strains viz., $X$. axonopodis (Fig. 5) and B. pertussis (Fig. 6) have been tested with different solvent (non-polar and polar) extracts of E. crassipes (Table 2). Maximum antibacterial activity against $X$. axonopodis was recorded for methanolic extracts of stem $\left(12 \pm 1.00^{\mathrm{a}} \mathrm{mm}\right)$ by contrast against pathogenic strain $B$. pertussis maximum activity was recorded leaf methanolic extracts $\left(17 \pm 1.00^{\mathrm{a}} \mathrm{mm}\right)$. Similar ability of aqueous extracts of root and stem was recorded against $B$. pertussis $(7 \pm 2.00 \mathrm{~mm})$ but against $X$ axonopodis maximum inhibition of zone was showed by leaf aqueous extracts $\left(9 \pm 1.00^{\mathrm{a}} \mathrm{mm}\right)$. In the current antibacterial assay, the ability of petroleum ether (root) and aqueous distilled water (leaf) extracts of this weed to inhibit the activity of $X$. axonopodis was determined $(9 \pm$ $\left.1.00^{\mathrm{a}} \mathrm{mm}\right)$ and $\left(9 \pm 1.00^{\mathrm{a}} \mathrm{mm}\right)$ respectively. Transitional values of zone of inhibition i.e., $6.66 \pm 1.52^{\mathrm{c}} \mathrm{mm}$ and $8 \pm$ $1.00^{\mathrm{bc}} \mathrm{mm}$ respectively were showed by extract of leaf in distilled water and petroleum ether.

Research reports demonstrated that plants including aquatic plants produce a range of naturally occurring known therapeutic compounds having anticancer and antimicrobial properties, which are toxic to microbes. Cytotoxic and antimicrobial activities of different parts of E. crassipes plant extracts have also been validated in different literature. Several of such annotations have helped in categorization and classification of these active constituents, which helped in production of new antimicrobial drugs, whereas such compounds have also been reported to use as food and feed (Vasu et al., 2009; Lata et al., 2010; Kurup et al., 2013; Kumar et al., 2014; Zohra et al., 2016; Chang and Chen, 2016). Current study supports the arguments of many researchers that various extracts of this weed have antimicrobial potential like methanolic, crude and aqueous extracts of parts of plant. Our results are in accordance with Baral and Vaidya (2011) reported the better efficacy of methanolic extracts against bacteria while aqueous extracts showed relatively better results against different fungi. Similarly results documented by Jayanthi and Lalitha (2013) strong antimicrobial activity in solvent extracts of E. crassipes which also strongly supports our current results. Previously, such results were also reported by Fareed et al. (2008) where different solvents were employed like ethanol, methanol and aqueous extracts for different parts of the E. crassipes (roots and leaves) to exploit its efficacy against different bacterial and fungal pathogen and aqueous extracts performed well as compared to other. Such difference against the pathogen by a similar extract might be due to their reliance against the pathogen by a similar extract might be due to their reliance on $\mathrm{pH}$, concentration of extract and time duration (Kurup et al., 2013; Zohra et al., 2016).

Antioxidant activity: Data presented in Table 2 depict the antioxidant and radical scavenging activity with DPPH assay of different extracts of E. crassipes by using non-polar-solvents like petroleum ether, chloroform and polar like methanol and dist. water. Antioxidants perform as free radical scavengers that foil and healing the damage done by the free radicals. The total antioxidant assay was accomplished with various plant extracts to analyse them qualitatively. The standards were used to compare the results of plant extracts. Hence they can be used as standards. E. crassipes root in petroleum ether extract showed value equal to the standard chemical $\alpha$ Tocopherol its value is 0.513 and hence can be used as standard. While E. crassipes stem in petroleum ether and chloroform extract showed lowest antioxidant values i.e., $0.33 \pm 0.12^{\mathrm{a}}$ and $0.44 \pm 0.09^{\mathrm{a}}$ respectively and stem in methanol extract showed value $0.45 \pm 0.12^{\mathrm{a}}$ which is close to the standard chemical BHT whose value is 0.476 . 
The distilled water extract of E. crassipes leaves showed highest antioxidant value $0.58 \pm 0.09^{a}$. Being stable nitrogen-cantered free radical, DPPH is used for estimation of radical scavenging activity of different parts of plant extracts. The obtained results of plant extracts were being matched with standard antioxidant available. E. crassipes root in chloroform extract showed highest value i.e., $0.53 \pm 0.08^{\mathrm{a}}$ and in methanol extract root showed lowest value i.e., $0.34 \pm 0.08^{\mathrm{a}}$ while stem in petroleum ether extract showed lowest value i.e., $0.33 \pm$ $0.12^{\mathrm{a}}$. The leaves in distilled water and petroleum ether extract showed highest antioxidant value $0.58 \pm 0.09^{\mathrm{a}}$ and $0.54 \pm 0.07^{\mathrm{ab}}$ respectively and overall all extracts showed higher values than standards so cannot be taken as standard because it do not resemble to the standard $\alpha$ Tocopherol and BHT as presented in Table 2. While, flavonoids have sturdy anti-cancerous activity and its free radical scavengers avert oxidative cell damage, have sturdy anticancer activity (Salah et al., 1995; Lata and Dubey, 2010a, 2010b). Our results depict that this aquatic weed had strong antioxidants potential which is in line with the previous findings that $E$. crassipes (Mart.) Solms possess many antioxidants like ascorbic acid, glutathione etc (Kurup et al., 2013; Lalitha and Jayanthi, 2014). Whereof, similar results were also reported by Subedi et al. (2012) that antioxidant helps in treatment of disorders like cardiovascular disease, ageing, cancer, rheumatoid arthritis and diabetes.

Phytochemical Analysis: The present research paper illustrates qualitative analysis of the E. crassipes parts viz., root, stem and leaf extracts with different non-polar and polar solvents which revealed the presence of many important constituents by using standard procedures are summarized in (Table3). Phytochemical screening of extracts revealed the indication of alkaloids, coumarins, terpenoids, tannins and flavonoides, in contrast to saponins, anthrax-quinones, phlobatanins and cardiac glycosides which were found absent. Considerable research efforts have been headed to evaluate and exploit the presence of such secondary metabolites in other aquatic weeds including E. crassipes (Rio et al., 1997; Okwu and Josiah, 2006; Vasu et al., 2009; Pepsi et al., 2012; Rajeshwari et al., 2014). Similar results were documented by many researchers for the presence of flavonoids, terpenoids, alkaloids and tannins and these are reported as a source of antioxidants in the weed water hyacinth (Nyananyo and Ogamba, 2005; Jayanthi et al., 2011; Lalitha et al., 2012, 2013; Kurup et al., 2013; Tulika and Mala, 2015). In contrast to Lalitha et al. (2012) our results showed absence of cardiac glycosides. Beside Vasu et al. (2009) reported the existence of saponins and absence of flavonoids likewise, Vasu et al. (2009) also reported the absence of flavonoids whereof, presence of phenols, alkaloids, steroids, triterpenoids and tannins in the methanol extract of E. crassipes which is contradiction to our results where saponins were absent but flavonoids and terpenoids were present. Our results are also in line with Lata et al. (2010) who assessed the absence of saponins but presence of few secondary metabolites in aqueous extracts of this weed. Such contradictions may be due to variations in geographical regions like minerals in soil and environmental factors which have significant influence on phytochemical contents of the water weed (Chakrabarthy, 2009: Lata and Dubey, 2010a, 2010b; Jayanthi et al., 2011; Borokini and Ayodele, 2012). The analysis of this study evidenced that $E$. crassipes shows potential for different phytochemical which act as secondary metabolites and are bioactive constituents hence this aquatic weed is a valuable reservoir of secondary metabolites which have active role in scavenging the deleterious effects of reactive oxygen species and also have compounds of substantial medicinal merit.

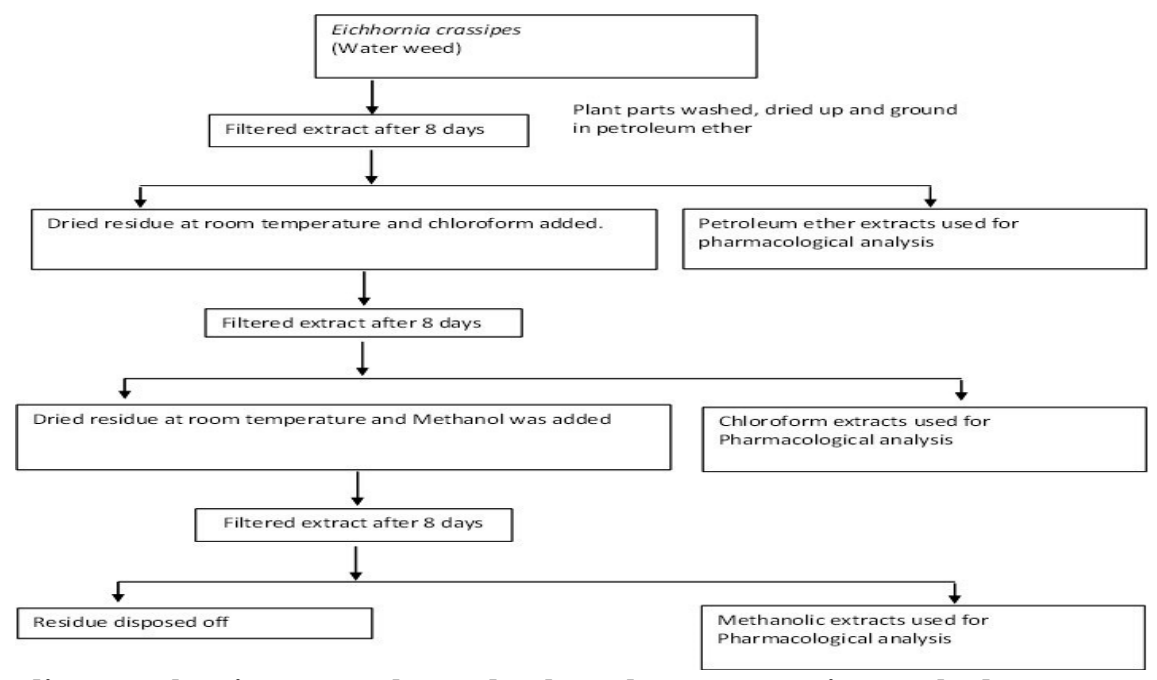

Fig.1. Overall flow diagram showing non-polar and polar solvents extraction method. 
Table 1. Zone of inhibition (diameter in $\mathbf{m m}$ ) formed by root, stem and leaf of $E$. crassipes extracts against fungal (Penicillium italicum and Botrytis cinerea) and bacterial (Xanthomonas axonopodis and Bordetella pertussis) pathogens in various non-polar (petroleum ether, chloroform) and polar (methanol and distilled water) solvents.

\begin{tabular}{|c|c|c|c|c|c|}
\hline \multirow{3}{*}{$\begin{array}{c}\text { Solvents } \\
\text { (non-polar and } \\
\text { polar) }\end{array}$} & \multirow{3}{*}{$\begin{array}{l}\text { Plant } \\
\text { parts }\end{array}$} & \multicolumn{4}{|c|}{ Diameter of inhibition zone (mm)according to microorganism } \\
\hline & & \multicolumn{2}{|c|}{ Fungal strains } & \multicolumn{2}{|c|}{ Bacterial strains } \\
\hline & & P. italicum & B. cinerea & $\begin{array}{l}\text { X. axonopodis } \\
\text { (Gram-negative) }\end{array}$ & $\begin{array}{l}\text { B. pertussis } \\
\text { (Gram-negative) }\end{array}$ \\
\hline Petroleum ether & \multirow{5}{*}{ Root } & $24 \pm 1.00^{\mathrm{a}}$ & $10 \pm 1.00^{b}$ & $9 \pm 1.00^{\mathrm{a}}$ & $6.66 \pm 1.52^{\mathrm{a}}$ \\
\hline Chloroform & & $11 \pm 1.00^{\mathrm{d}}$ & $8 \pm 1.00^{\mathrm{c}}$ & $6 \pm 1.00^{b}$ & $6 \pm 1.00^{\mathrm{a}}$ \\
\hline Methanol & & $13.6 \pm 1.52^{\mathrm{c}}$ & $6 \pm 1.00^{\mathrm{d}}$ & $6 \pm 1.00^{b}$ & 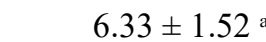 \\
\hline Distilled Water & & $16 \pm 1.00^{\mathrm{b}}$ & $24 \pm 1.00^{\mathrm{a}}$ & $6.33 \pm 1.52^{\mathrm{b}}$ & $7 \pm 2.00 \mathrm{a}$ \\
\hline Petroleum ether & & $6 \pm 1.00^{\mathrm{c}}$ & $6 \pm 1.00^{\mathrm{c}}$ & $6 \pm 1.00^{b}$ & $6.66 \pm 1.52$ \\
\hline Chloroform & \multirow{3}{*}{ Stem } & $11 \pm 1.00^{b}$ & $15 \pm 1.00^{b}$ & $6.66 \pm 1.52^{b}$ & $6 \pm 1.00^{a}$ \\
\hline Methanol & & $11 \pm 1.00^{b}$ & $12 \pm 1.00^{\mathrm{c}}$ & $12 \pm 1.00^{\mathrm{a}}$ & 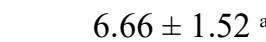 \\
\hline Distilled Water & & $20.3 \pm 1.52^{\mathrm{a}}$ & $9.3 \pm 1.52^{b}$ & $8 \pm 1.00^{\mathrm{b}}$ & $7 \pm 2.00^{\mathrm{a}}$ \\
\hline Petroleum ether & \multirow{4}{*}{ Leaf } & $6.33 \pm 1.52^{\mathrm{c}}$ & $6 \pm 1.00^{\mathrm{c}}$ & $6.66 \pm 1.52^{\mathrm{a}}$ & $8 \pm 1.00 \mathrm{bc}$ \\
\hline Chloroform & & $23 \pm 1.00^{\mathrm{a}}$ & $29 \pm 1.00^{\mathrm{a}}$ & $6.66 \pm 2.08 \mathrm{a}$ & $10.6 \pm 2.08$ \\
\hline Methanol & & $11 \pm 1.00^{b}$ & $6 \pm 1.00^{\mathrm{c}}$ & $7 \pm 2.00^{a}$ & $17 \pm 1.00^{\mathrm{a}}$ \\
\hline \multirow[t]{4}{*}{ Distilled Water } & & $10 \pm 1.00^{b}$ & $24.3 \pm 1.52^{\mathrm{b}}$ & $9 \pm 1.00^{\mathrm{a}}$ & $6.66 \pm 1.52^{\circ}$ \\
\hline & & \multicolumn{2}{|c|}{ Standard discs employed } & \multicolumn{2}{|c|}{ Standard discs employed } \\
\hline & & Fuconazole & Kanamycin & Ampicillin & Amikacin \\
\hline & & $53.66 \pm 1.50$ & $50 \pm 1.20$ & $19.5 \pm 2.12$ & $22.5 \pm 3.21$ \\
\hline
\end{tabular}

$\mathrm{LSD}=1.28$ each value is an average of three replicates \pm followed by standard deviation of each row and column.

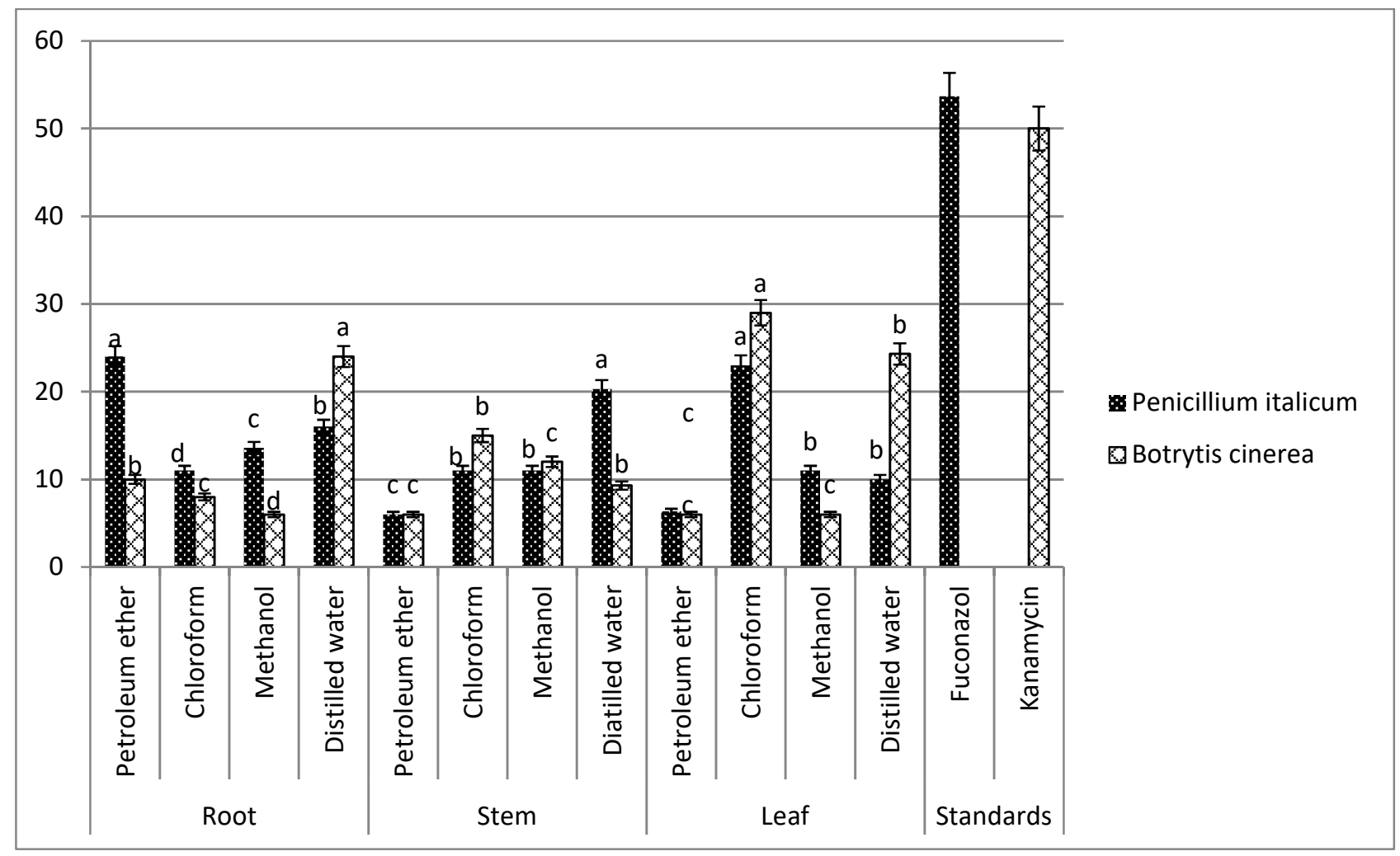

(a) 


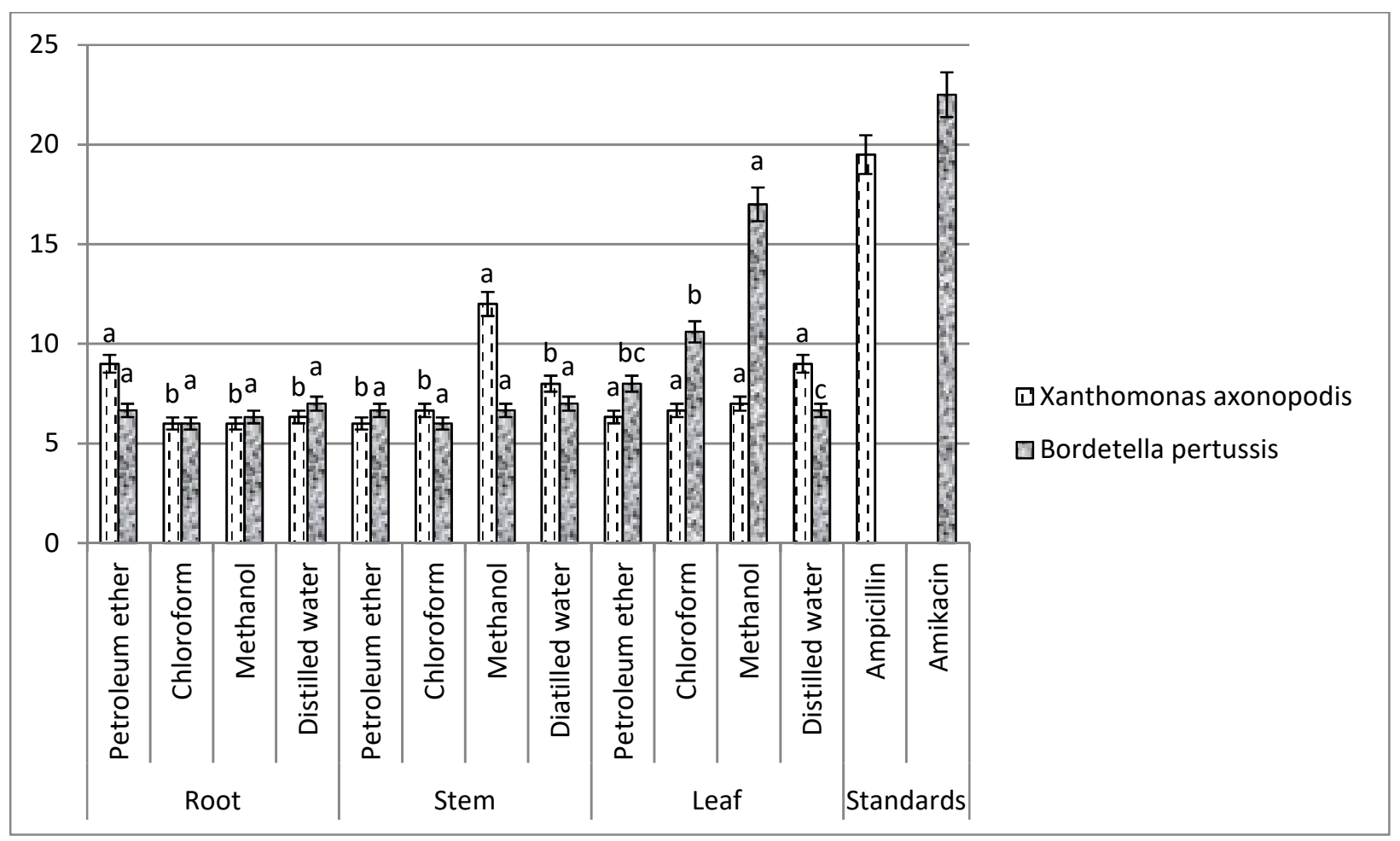

(b)

Fig. 2. Comparison of zone of inhibition ( $\mathrm{mm}$ ) between two (a) fungal pathogen viz. P. italicum and B. cinerea and (b) bacterial strains viz. $X$. axonopodis and $B$. pertussis.

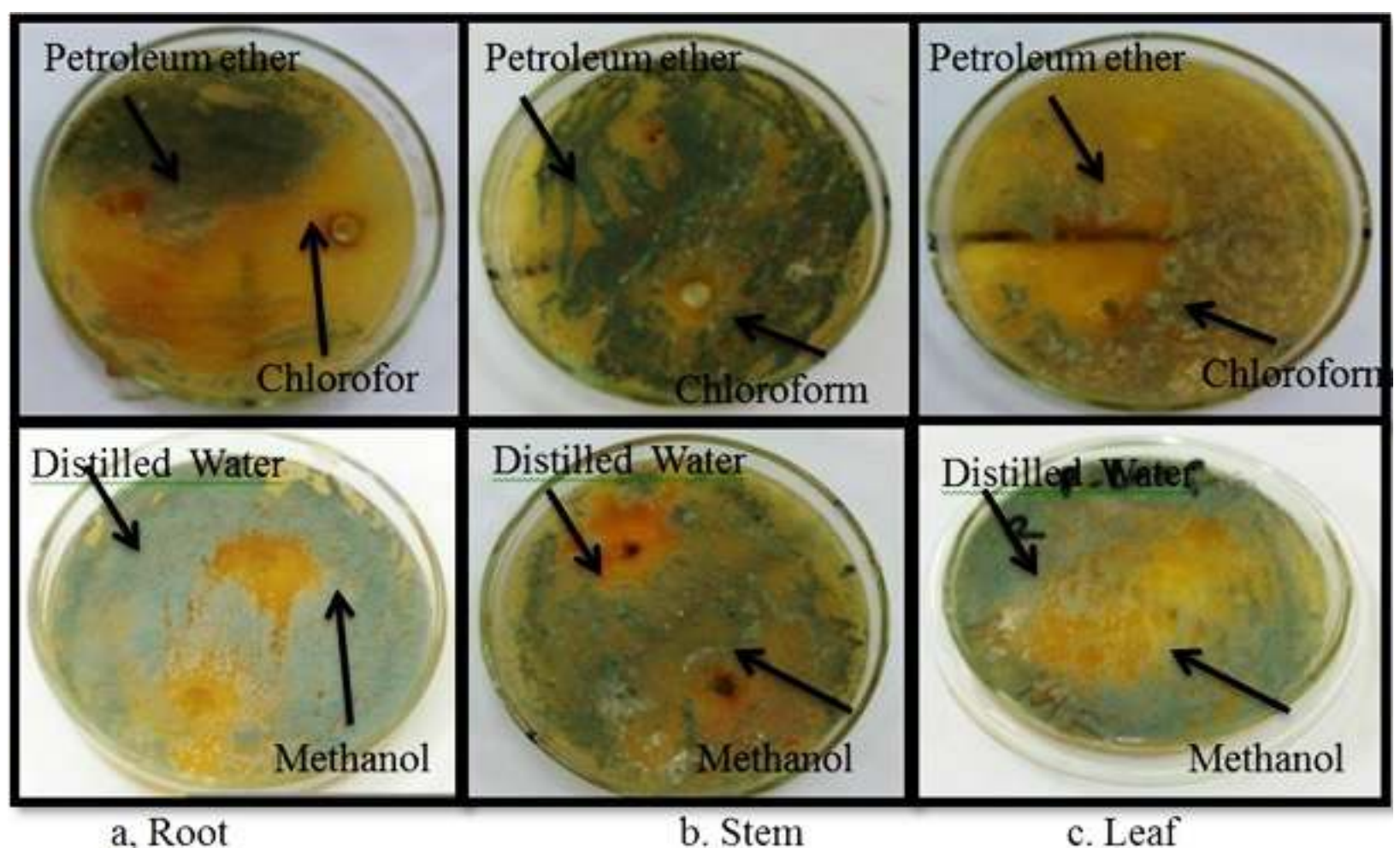

Fig. 3. Antifungal activity of Eichhornia crassipes (Mart.) Solms various parts (a) root, (b) stem and (c) leaf extracts in various non-polar i.e., petroleum ether, chloroform and polar methanol and distilled water solvents against Penicillium italicum. 

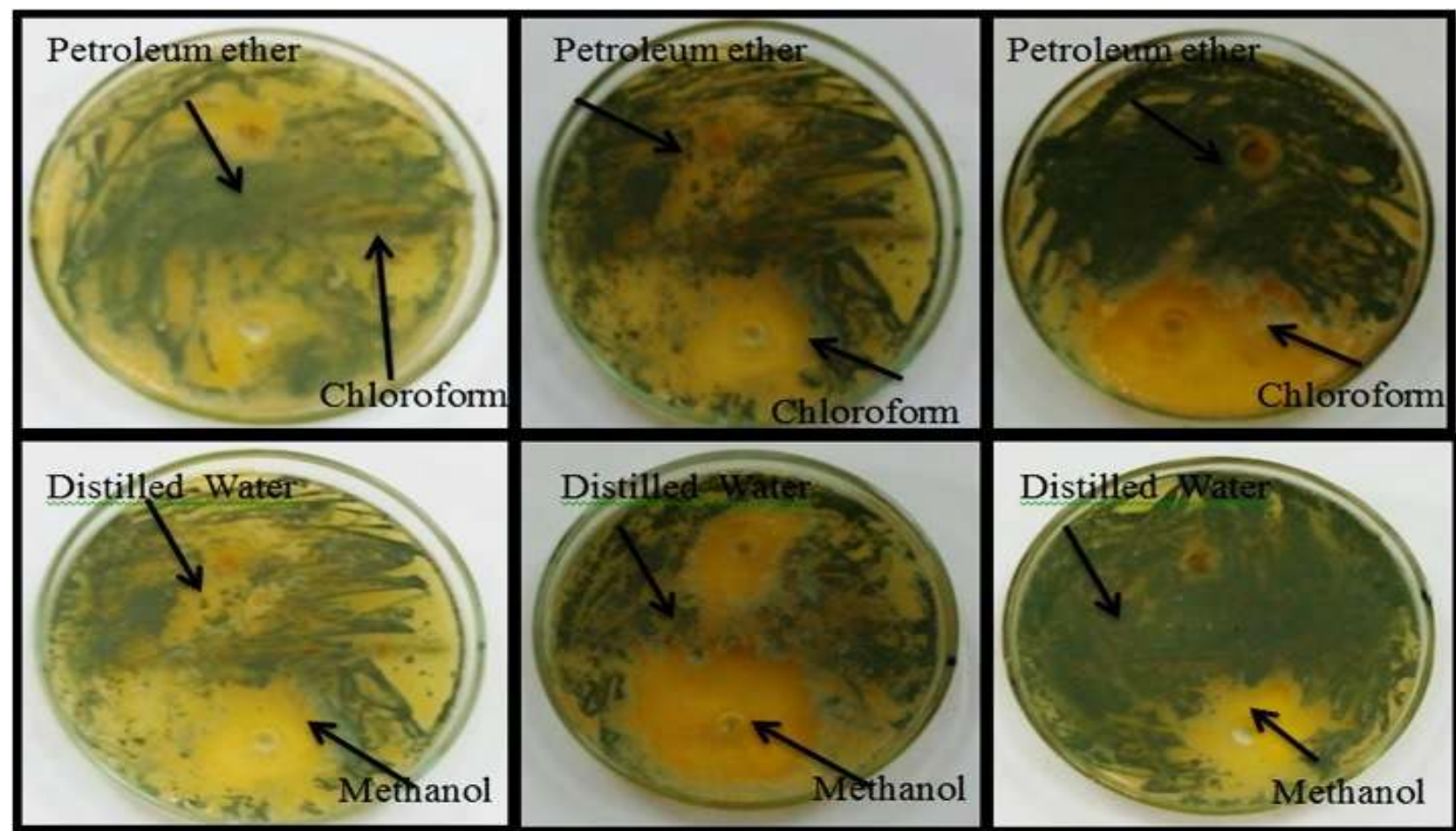

a. Root

b. Stem

c. Leaf

Fig. 4. Antifungal activity of Eichhornia crassipes (Mart.) Solms various parts (a) root, (b) stem and (c) leaf extracts in various non-polar i.e., petroleum ether, chloroform and polar methanol and distilled water solvents against against Botrytis cinerea.

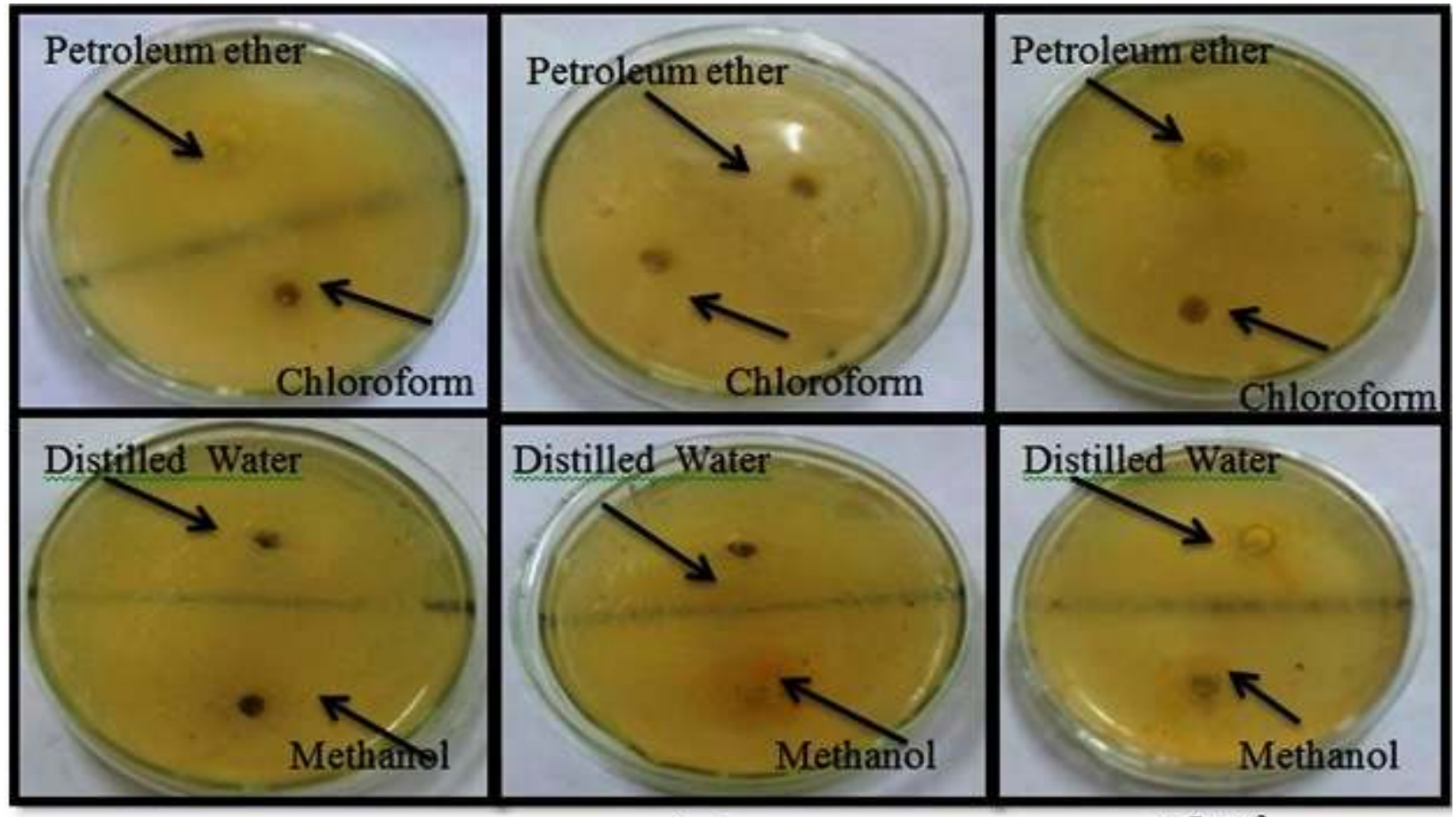

a. Root

b. Stem

c. Leaf

Fig. 5. Antibacterial activity of Eichhornia crassipes (Mart.) Solms various parts (a) root, (b) stem and (c) leaf extracts in various non-polar i.e., petroleum ether, chloroform and polar methanol and distilled water solvents against against Xanthomonas axonopodis. 


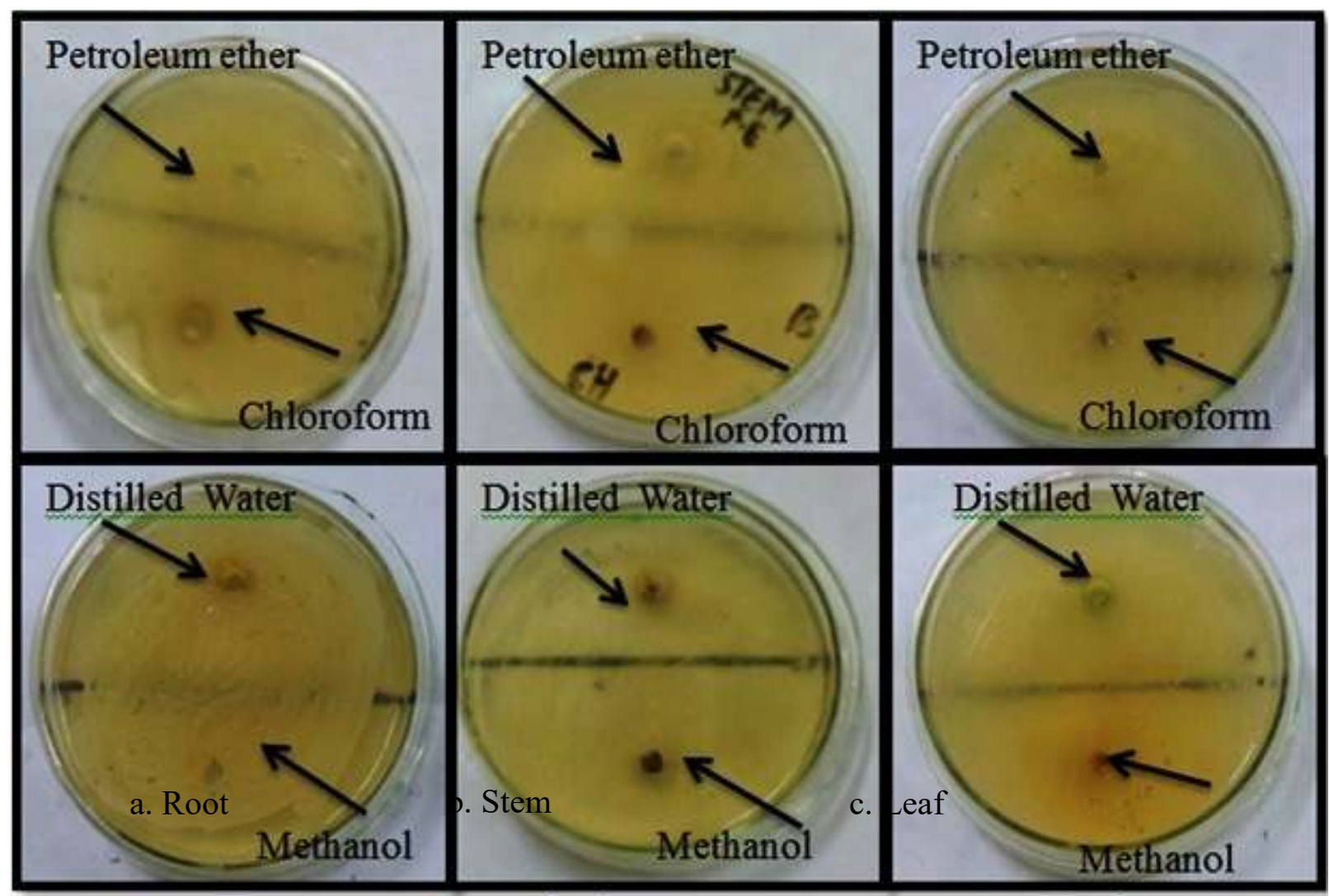
a. Root
b. Stem
c. Leaf

Fig. 6. Antibacterial activity of Eichhornia crassipes (Mart.) Solms various parts (a) root, (b) stem and (c) leaf extracts in various non-polar i.e., petroleum ether, chloroform and polar like methanol and distilled water solvents against Bordetella pertussis.

Table 2. Antioxidant activity of $E$. crassipes (root, stem and leaf) in different non-polar and polar solvents (petroleum ether, chloroform, methanol and aqueous distilled water extracts) by using (i) total antioxidant assay and (ii) DPPH assay.

\begin{tabular}{|c|c|c|c|}
\hline \multirow{3}{*}{$\begin{array}{c}\text { Solvents } \\
\text { (non-polar and polar) }\end{array}$} & \multirow{3}{*}{ Plant parts } & \multicolumn{2}{|c|}{ Antioxidant activity } \\
\hline & & (i) Total Antioxidant assay & (ii) DPPH assay \\
\hline & & Absorption at $695(\mathrm{~nm})$ & Absorption at $517(\mathrm{~nm})$ \\
\hline Petroleum Ether & Root & $0.51 \pm 0.09^{\mathrm{a}}$ & $0.51 \pm 0.09^{\mathrm{a}}$ \\
\hline Chloroform & & $0.53 \pm 0.08^{b}$ & $0.53 \pm 0.08^{a}$ \\
\hline Methanol & & $0.33 \pm 0.09^{b}$ & $0.34 \pm 0.08^{\mathrm{a}}$ \\
\hline Distilled Water & & $0.53 \pm 0.10^{\mathrm{a}}$ & $0.52 \pm 0.09^{\mathrm{a}}$ \\
\hline Petroleum Ether & Stem & $0.33 \pm 0.12^{\mathrm{a}}$ & $0.33 \pm 0.12^{\mathrm{a}}$ \\
\hline Chloroform & & $0.44 \pm 0.09^{\mathrm{a}}$ & $0.46 \pm 0.07 \mathrm{a}$ \\
\hline Methanol & & $0.45 \pm 0.12^{\mathrm{a}}$ & $0.46 \pm 0.10^{\mathrm{a}}$ \\
\hline Distilled Water & & $0.46 \pm 0.09^{\mathrm{a}}$ & $0.46 \pm 0.09^{\mathrm{a}}$ \\
\hline Petroleum Ether & Leaf & $0.54 \pm 0.07 \mathrm{ab}$ & $0.54 \pm 0.07^{\mathrm{ab}}$ \\
\hline Chloroform & & $0.33 \pm 0.13 \mathrm{ab}$ & $0.33 \pm 0.13 \mathrm{ab}$ \\
\hline Methanol & & $0.42 \pm 0.11^{\mathrm{b}}$ & $0.42 \pm 0.12^{\mathrm{b}}$ \\
\hline Distilled Water & & $0.58 \pm 0.09^{\mathrm{a}}$ & $0.58 \pm 0.09 a$ \\
\hline & & $\alpha$ - Tocopherol $=0.513$ & $\alpha-$ Tocopherol $=0.095$ \\
\hline Standards & & Butyl hydroxytouline $=0.476$ & Butyl hydroxytouline $=0.190$ \\
\hline & & Blank $=0.026$ & Blank $=0.0035$ \\
\hline
\end{tabular}

Note: Each value is an average of three replicates \pm followed by standard deviation of each row and column. 
Table 3. Screening of phytochemicals of $E$. crassipes parts viz. root, stem and leaf..

\begin{tabular}{llccc}
\hline S. \# & Phytochemical (indications) & Root & Stem & Leaf \\
\hline 1 & Alkaloids (Creamish ppt.) & ++ & ++ & ++ \\
2 & Saponins (Persistent froth) & - & - & - \\
3 & Anthraquinones (Pink froth) & - & - & - \\
4 & Coumarins (Yellow flouresence) & + & +++ & +++ \\
5 & Terpenoids (Blue-green ring) & ++ & +++ & +++ \\
6 & Flavonoids (Dark yellow colour) & ++ & +++ & ++ \\
7 & Tannins (Brownish colour) & +++ & +++ & + \\
8 & Phlobatannins (Red ppt.) & - & - & - \\
9 & Cardiac glycosides (Blue green color) & - & - & - \\
\hline Indicators: $\quad+++=$ very high quantities; $++=$ high quantities; $+=$ low quantities; $-=$ not detectable.
\end{tabular}

Conclusion: From the current study it is being concluded that selected water weed showed significant antimicrobial and antioxidant activity along with beneficial phytochemical whilst, results were being compared with the commercially available standards. The statistical analysis performed depicts that both stem and leaf extracts are more potent antimicrobial agent as compared to root extracts. Thus, comprehensive pharmacokinetic research is warranted to determine the dose and efficacy of biologically active compounds and its pattern of disposition. Nonetheless, presence of phytochemical in this worst aquatic weed and appreciable antioxidant and antimicrobial activity makes it a valuable plant because there is call for isolation and purification of active constituents of the plant extracts which show significant antimicrobial activity in order to develop future pharmaceuticals.

Conflict of interest: Authors have no conflict of interest with any other.

\section{REFERENCES}

Agunbiade, F.O., B.I.Olu-Owolabi and K.O. Adebowale (2009). Phytoremediation potential of Eichornia crassipes in metal-contaminated coastal water. Biores. Technol. 100: 4521-4526.

Ali, H., M. Patel, N. Ganesh and J. Ahi (2009). The world's worst aquatic plant as a safe cancer medicine, antitumor activity on melanoma induced mouse by Eichornia crassipes: in vivo studies. J. Pharm. Res. 2: 1365-1366.

Attermeyer, K. S. Flury, R. Jayakumar, P. Fiener, K. Steger, V. Arya, F. Wilken, R. van Geldern and K. Premke (2016). Invasive floating macrophytes reduce greenhouse gas emissions from a small tropical lake. Sci. Rep. 6: 20424.

Baral, B. and G.S. Vaidya (2011). Biological and chemical assessment of water hyacinth Eichhornia crassipes (Mart.) Solms. of Phewa Lake, Nepal. Sci. World. 9(9): 57-62.
Barrett, S.C.H. (2015). Influences of clonality on plant sexual reproduction. PNAS. 112(29): 88598866.

Borokini, T.I. and A.E. Ayodele (2012). Phytochemical screening of Taccaleonto petaloides (L.) Kuntze collected from four geographical locations in Nigeria. Int. J. Modern. Bot. 2: 97-102.

Center, T.D., F.A. Dray, G.P. Jubinsky and M.J. Grodowitz. (1999). Biological control of water hyacinth under condition of maintenance management: Can herbicides and insects be integrated? Environ. Manage. 23: 241-256.

Chakrabarthy, H. (2009). Fisheries and Aquaculture, Technical Paper No. 531, Rome, FAO.

Chang, C. and W. Chen (2016). Multiple dietary administrating strategies of water hyacinth (Eichhornia crassipes) on enhancing the immune responses and disease resistance of giant freshwater prawn, Macrobrachium rosenbergii. Aquacul. Res.47: 140-152.

Edwards, P., Kamal, M. and K.L. Wee (1985). Incorporation of composted and dried water hyacinth in pelleted feed for the tilapia Oreochromis niloticus (Peters). Aquacul. Res. 16: 233-248.

Erasto, P.G., R.R. Bojase-Moleta and T. Majinda (2004). Antimicrobial and antioxidant flavonoids from the root wood of Bolsanthus speciosus. Phytochem. 65(1): 875-880.

Fareed, M.F., A.M. Haroon and S.A. Rabeh (2008). Antimicrobial activity of some macrophtyes from Lake Manzalah (Egypt). Pakistan J. Biol. Sci. 11: 2454-2463.

Ferreria, M.J.U., A. Duarte and J.R. Ascenso (1996). Antimicrobial activity and phytochemical studies tuckeyana. Fitoterapia. 37:85-86.

Jafari, N. (2010). Ecological and socio-economic utilization of water hyacinth (Eichhornia crassipes Mart. Solms.), J. Appl. Sci. Environ. Manage. 14(2): 43-49.

Jamil, M., B. Mirza, A. Yasmeen and M.A. Khan (2012). Pharmacological activities of selected plant 
species and their phytochemical analysis. J. Med. Plant Res. 6 (37): 5013-5022.

Jayanthi, P. and P. Lalitha (2013). Antimicrobial activity of solvent extracts of Eichhornia crassipes (Mart.) Solms. Der Pharma Chemica. 5(3): 135140.

Jayanthi, P., P. Lalitha and K.S. Shubashini (2011). Phytochemical investigation of the extracts and the solvent fractionates of the aqueous extract of Eichhornia crassipes. J. Pharm. Res. 4: 14051406.

Kumar, S., A. Mishra and A.K. Pandey (2013). Antioxidant mediated protective effect of Parthenium hysterophorus against oxidative damage using in vitro models. BMC Complementary Altern. Med. 13(1): 120.

Kumar, S. and A.K. Pandey (2013). Chemistry and biological activities of flavonoids: an overview. Sci. World J. 1-16.

Kumar, S., R. Kumar, A. Dwivedi and A.K. Pandey (2014). In vitro antioxidant, antibacterial, and cytotoxic activity and in vivo effect of Syngonium podophyllum and Eichhornia crassipes leaf extracts on isoniazid induced oxidative stress and hepatic markers. BioMed Res. Int. 1-11.

Kurup, A.R., D. Rajan, D.J. Blesson, S. Chandran, A. Thampatty and P.V. Veena (2013). Detailed analysis on phytochemical, antioxidants, antimicrobial activity of Eichhornia cassipes. Biotechnol. 2(2): 17-19.

Lalitha, P. and P. Jayanthi (2014). Antiaging activity of the skin cream containing ethyl acetate extract of Eichhornia crassipes (Mart.) Solms. Int. J. Pharm. Technol. Res. 6(1): 29-34.

Lalitha, P., P. Jayanthi, R. Sujitha and A. Thamaraiselvi (2013). Anti-Inflammatory activity of the various solvent extracts of Eichhornia crassipes (Mart.) Solms. Int. J. Pharm. Technol. Res. 5(2): 641-645.

Lalitha, P., S.K. Sripathi and P. Jayanthi (2012). Secondary metabolites of Eichhornia crassipes (water hyacinth): A review (1949 to 2011). Natural Product commun. 7(9): 1249-1256.

Lata, N. and V. Dubey (2010a). Preliminary phytochemical screening of Eichhornia crassipes: the world's worst aquatic weed. J. Pharm. Res. 6: 1240-1242.

Lata, N. and V. Dubey (2010b). Antioxidants of Eichhornia crassipes: The World's worst aquatic weed. Int. J. Contemporary Res. Rev.1: 1-5.

Lata, N., H. Ali, D. Sumana and V. Dubey (2010). Antioxidants of Eichhornia crassipes: The world's worst aquatic plant. J. Pharm. Res. 3: 2105-2106.
Li, X., Y. Zhou,Y. Yang, S. Yang, X. Sun and Y. Yang (2015). Physiological and proteomics analyses reveal the mechanism of Eichhornia crassipes tolerance to high-concentration cadmium stress compared with Pistia stratiotes. PLoS ONE. 10(4): 1-22.

Linderschmidt, R., A. Trylka, M. Goad and H. Witschi (1986). The effects of dietary butylated hydroxytoluene on liver and colon tumor development in mice. Toxicol. 38: 151-160.

Liu, C.C., G.L. Zhao, Y.N., Li, Z.P., Ding, Q.G. Liu and J.L., Li (2010). Contribution of phenolics and flavonoids to anti-oxidant activity of ethanol extract from Eichhornia crassipes. Adv. Mat. Res. 156(157): 1372-1377.

Nyananyo, G.A.H. and E.N. Ogamba (2005). The Physico-chemistry and distribution of water hyacinth (Eichhornia crassipes) on the river Nun in the Niger Nelta. J. Appl. Environ. Manage. 11: 133-137.

Olukemi, O.A., I.O. Olukemi, S.M. Oluwatoyin, A.O. Austin, L.B. Mansurat and T.I. Olufunmilola (2005). Antioxidant activity of Nigerian dietary spices. Electron. J. Environ. Agric. Food. Chem. 4: 1086-1093.

Okwu, D.E. and C. Josiah (2006). Evaluation of the chemical composition of two Nigerian medicinal plants. Afr. J. Biotechnol. 5(4): 357-361.

Pandey, D.K. (2015). Allelochemicals from Parthenium for water hyacinth control. Ind. J. weed Sci. 47(3): 321-328.

Pepsi, A., C.P. Ben and S. Jeeva (2012). Phytochemical analysis of four traditionally important aquatic species. Int. Res. J. Biological Sci. 1(5): 66-69.

Pramila, G., D.B. Jirekar, M. Farooqui and S.D. Naikwade (2014). Biological activity of aqueous extract of some medicinal plants. Der Chemica. Sinica. 5(4): 65-70.

Prieto, P., M. Pineda and M. Agular (1999). Spectrophotometric quantitation antioxidant capacity through the formation of a phosphormolybednum complex. Anal. Biochem. 269: 337-341.

Qadeer, M.A., A. Rehman, J.M. Iqbal and M. Ahmed (1990). Studies on the extracellular enzymes by Bacills subtilis. J. Pure Sci. 1(9): 11-17.

Rajeshwari, C.U., R.I. Shobhaand and B. Andallu (2014). Phytochemicals in diet and human health with special reference to polyphenols. Ann. Phytomed. 3(2): 4-25.

Rio, D.A, B.G. Obdululio, J. Casfillo, F.G. Marin and A. Ortuno (1997). Uses and Properties of citrus flavonoids. J. Agric. Food Chem. 45: 45054515.

Salah. N., N. J. Miller, G. Pagange, L.Tijburg, G.P. Bolwell, E. Rice and C. Evans (1995). 
Polyphenolic flavonoils as scavenger of aqueous phase radicals as chain breaking antioxidant. Arch. Biochem. Broph. 2: 339-346.

Snedecor, G. and W. G. Corchan (1980). Statistical methods. $7^{\text {th }}(\mathrm{Ed})$. IOWA State University USA., Pp: 80-86.

Sanitha, B. (2005). Phytochemical screening and pharmacological evaluation of Eichhornia crassipes (Martius) Solmslaubach. MFSc dissertation, CIFE, Mumbai, India.

Sobedio, J. L., J. Kaitaramita, A. Grandgiral and Y. Malkkl (1991). Quality assessment of industrial pre-fried french fries. J. Am. Oil. Chem. Soc. 68: 299-302.

Subedi, A., M.P. Amatya, T.M. Shrestha, S.K. Mishra and B.M. Pokhrel (2012). Antioxidant and antibacterial activity of methanolic extract of Machilus odoratitissima. Kathmandu University. J. Sci. Eng. Technol. 8(1): 73-80.

Surendraraj, A., K.H.S. Farvin and R. Anandan (2013). Antioxidant potential of water hyacinth (Eichornia crassipes): In vitro antioxidant activity and phenolic composition. J. Aqua. Food Product Technol. 22: 11-26.

Tulika, T. and A. Mala (2015). Pharmaceutical potential of aquatic plant Pistia stratiotes (L.) and Eichhornia crassipes. J. Plant Sci.SI: Med Plants. 3(1-1): 10-18.

Vasu, K., J.V. Goud, A. Suryam and M.A.S. Charya (2009). Biomolecular and phytochemical analyses of three aquatic angiosperms. Afr. J. Microbiol. Res. 3(8): 418-421.

Yagi, K. (1987). Lipid peroxides and human diseases. Chem. Phys. Lipids. 45: 337-351.

Yen, G.C. and H.Y. Chen (1995). Antioxidant activity of various tea extracts in relation to their antimutagenicity. J. Agri. Food. Chem. 43: 2732.

Zohra, R., O.M. Redha and L.S. Eddine (2016). Evaluation of phenolic content and antioxidant capacity of leaf extract from Phoenix Dactylifera L. obtained by different $\mathrm{pH}$ of aqueous extraction. J. Pharm. Res. 10(1): 1-7. 